\title{
8 Research Square \\ Genetic Polymorphism and Intravenous Immunoglobulin Resistance Relationship in Kawasaki Disease
}

\section{Yusuf Ziya Varlı}

Basaksehir Cam and Sakura City Hospital, University of Health Science https://orcid.org/0000-0001-96483796

\section{Ahmet Okay Caglayan}

Dokuz Eylul University Faculty of Medicine: Dokuz Eylul Universitesi Tip Fakultesi

\section{Kaya Bilguvar}

TC Saglik Bakanligi Diyarbakir Devlet Hastanesi: Diyarbakir Selahaddin Eyyubi Devlet Hastanesi

Murat Gunel

Yale-New Haven Hospital

Kazim Oztarhan ( $\nabla$ yzvarli@gmail.com )

Demiroglu Bilim University

\section{Research article}

Keywords: Kawasaki disease, SNP (Single Nucleotide Polymorphism), IVIG resistance

Posted Date: March 22nd, 2021

DOl: https://doi.org/10.21203/rs.3.rs-271170/v1

License: (9) (i) This work is licensed under a Creative Commons Attribution 4.0 International License. Read Full License 


\section{Abstract \\ Objective}

Kawasaki disease (KD) is an acute febrile systemic vasculitis and the most common cause of coronary artery aneurysm (CAA) in children. Intravenous immunoglobulin (IVIG) therapy is used to prevent fever and systemic inflammation. However, IVIG resistance is the most important risk factor of morbidity and mortality. It has been identified several single nucleotide polymorphisms (SNPs) related to IVIG resistance and this research aims to analyze these polymorphisms in our study population.

\section{Methods}

Patients diagnosed with KD (n:259) were analyzed retrospectively. Blood samples were taken from a randomized subgroup (n:97). Previously reported IVIG resistance related exonic SNPs at five different gene loci (IL16, TNFSF14, NFATC2, DERL3, SAMD9L) were evaluated by whole exome sequencing (WES).

\section{Results}

Between 2010-2019, 259 patients (male/female: 1,67) with KD were submitted to our clinic. CAA and IVIG resistance rates were $11.6 \%$ and $21.6 \%$, respectively. The risk of developing CAA was significantly increased in patients with IVIG resistance $(p<0.001)$. As a result, IVIG resistance frequency increased in the presence of three SNPs. These are "rs11556218"(p.Asn1147Lys), "rs344560"(p.Lys214Glu), "rs12479626"(p.His446Arg), and are located in IL16, TNFSF14, NFATC2 genes, respectively.

\section{Conclusions}

Until now, KD-related genetic data mostly obtained from studies involving large cohorts from Northeast Asian countries. In the analysis of this largest Turkish cohort in the literature, we found that, similar with previous studies, the IL 16 gene may be plays important role in the IVIG resistance mechanism.

\section{Introduction}

Kawasaki disease (KD) is an acute febrile systemic vasculitis of childhood, characterized by fever, bilateral nonexudative conjunctivitis, erythema in the lips and oral mucosa, changes in the peripheral periphery, rash and cervical lymphadenopathy. ${ }^{1-3}$

It is usually seen under five years of age and when not treated, it is reported that it develops $15-25 \%$ coronary artery aneurysm (CAA) or ectasia. ${ }^{2,3}$

It causes myocarditis and arrhythmia during the acute period. In subacute and chronic period, it causes myocardial infarction and sudden cardiac deaths due to CAA. Early diagnosis and treatment reduces the risk of coronary complications, morbidity and mortality rates significantly. ${ }^{1-4}$ 
The state-of-the-art treatment is high-dose intravenous immunoglobulin (IVIG) together with acetylsalicylic acid (ASA). ${ }^{2}$ Since resistance to intravenous immunoglobulin (IVIG) is associated with coronary artery lesions (CALs) in KD, it is crucial to identify patients at risk group to protect them from coronary involvement.

The definition of IVIG resistance is used to prevent the fever from falling or recurrence 36 hours after the end of treatment and its mechanism has not been fully elucidated. ${ }^{5}$ Unresponsiveness to IVIG, which is $10-20 \%$ in the literature, significantly increases the risk of developing coronary complications, and more aggressive treatments are needed in these patients. The researchers have developed different risk scoring systems over the years for various clinical and laboratory parameters for predicting the development of CAA with IVIG resistance in patients. ${ }^{6-9}$ Risk scoring systems used to predict IVIG resistance gave different results in different races, therefore, the effects of genetic factors on IVIG resistance development were investigated.

In recent years, thanks to the rapidly developing molecular genetic techniques, studies on detection of candidate genes and polymorphisms are continuing in terms of susceptibility to many diseases or response to treatment. Here, selected SNPs and thier associations with IVIG resistance in KD is investigated.

\section{Materials And Methods}

\section{Patients}

The study protocol was approved by the University of Health Science, Kanuni Sultan Süleyman Research and Training Hospital Human Investigation Committee (HIC) (protocol number 48865165-302.14.01). Informed consent forms were signed by the parents.

Between 2010 and 2019, patients were recruited in our clinic based on the diagnosis criterias of the American Heart Association (AHA) guidelines. ${ }^{2,3}$ A fever requirement of $\geq 5$ days for the diagnosis of typical KD and the presence of at least four of the five basic clinical findings were sought. ${ }^{2}$ Incomplete KD; defined for cases with fever lasting $\geq 4$ days and less than four criteria were met, with suspected laboratory and echocardiographic findings. ${ }^{2}$

The patients had an echocardiographic examination at the time of diagnosis and in the subacute period for the presence of coronary involvement and the risk of complications. Myocardial wall mobility, ejection fraction (\%), diameters of coronary arteries, and Z scores (calculated according to AHA guidelines) were recorded. The following findings were indicated by the $Z$ score calculation: dilation, $2<Z$ score $<2.5$ or if initially $<2$ and a decrease in $Z$ score during follow-up $\geq 1$; small aneurysm, $2.5 \leq Z$ score $<5$; moderate aneurysm, $5 \leq Z$ score $<10$; large or giant aneurysm, $Z$ score was defined as $\geq 10 .^{2}$ The examinations were performed by the same pediatric cardiologist as 2D, M mode, CW, and PW Doppler methods. A Vivid S5 with GE 3S and 6S probes (General Medical Electric Systems, Milwaukee, WI, USA) echocardiogram device was used.

According to the $Z$ score calculation, the following definitions were applied: dilation, $2<Z$ score $<2.5$ or if initially $<2$ and a decrease in $Z$ score during follow-up $\geq 1$; small aneurysm, $2.5 \leq Z$ score $<5$; moderate aneurysm, $5 \leq \mathrm{Z}$ score $<10$; and large or giant aneurysm, Z score was defined as $\geq 10{ }^{2}$ 
IVIG and aspirin were given in appropriate doses to all patients hospitalized with a diagnosis of KD according to AHA criteria as the standard primary treatment. ${ }^{2}$ IVIG resistance is defined as recurrent or permanent fever development at least $36 \mathrm{~h}$ after the end of the IVIG infusion. ${ }^{2}$

Gender, age at diagnosis, presence of diagnostic criteria, number of days with fever, and personal and family histories were recorded. The cases were grouped in terms of responses to IVIG treatment. Retrospective statistical comparisons were made between the groups.

\section{METHODS}

\section{DNA extraction}

Peripheral blood was collected from all participants in the subgroup of 97 cases and stored in PAXgene tubes. DNA isolation was performed using DNeasy Blood \& Tissue Kit (Cat No./ID: 69506; QIAGEN, Germany) from lymphocyte cells from blood samples taken from patients in accordance with the manufacturer' protocol.

\section{Whole Exome Sequencing}

After genomic DNA is sheared to a mean fragment length of about 220 bp using focused acoustic energy (Covaris E220), purification and then PCR amplification are achieved using custom-made primers (IDT). The DNA library was created according to manufacturer's protocol by IDT (xGen Exome Panel). Samples were sequenced on the S4 flow cells using Illumina NovaSeq6000. Primary analysis is performed using Illumina's CASAVA 1.8.2 software suite. $10 x$ target coverage was $>95 \%$.

SNPs in five different gene loci (IL16, TNFSF14, NFATC2, DERL3, SAMD9L) identified by recent study related to IVIG resistance were examined. ${ }^{10}$

Data were analyzed using (SPSS Statistics for Macintosh, version 24.0; IBM Corp., Armonk, NY, USA). Categorical variables were summarized using frequencies (percentage [\%]). The mean \pm standard deviation was used for continuous variables. Normality was assessed for continuous data using the KolmogorovSmirnov test. An independent samples t-test was used for continuous variables. Categorical variables were compared using a chi-squared test. A p-value $<0.05$ was taken as an indicator of statistical significance. Results and significance values are summarized in the relevant tables.

\section{Results}

During the study, 259 patients (Male / Female = 1.67) were recruited between 3 and 117 months of age. The clinical and demographic data of the patients in terms of responsiveness to IVIG treatment are summarized in the Table 1. IVIG resistance was observed in 56 cases (21.6\%). The mean age of patients with IVIG resistance was significantly younger than that of patients with IVIG response (Table 1). While IVIG unresponsiveness was significantly increased in the age group of infants, there was no difference in gender and type of diagnosis. There was a significant correlation between IVIG resistance and frequency of CAA development and hospitalization time $(p<0,001)$. The risk of developing coronary artery lesions especially in IVIG resistant patients appears to be significantly increased compared to those who are sensitive. (Table 1). 
Table 1

Demographic data of patients according to response to IVIG treatment

\begin{tabular}{|c|c|c|c|}
\hline \multirow[t]{2}{*}{ Variable } & \multicolumn{2}{|l|}{ IVIG responsiveness } & \multirow[t]{2}{*}{$p$ value } \\
\hline & Responders ( $n=203$ ) & Non-responders $(n=56)$ & \\
\hline \multicolumn{3}{|l|}{ Sex } & \multirow[t]{3}{*}{$0.762^{a}$} \\
\hline Male & $126(77.8 \%)$ & $36(22.2 \%)$ & \\
\hline Female & $77(79.4 \%)$ & $20(20.6 \%)$ & \\
\hline Age range (months) & $34.6(1.9-118.8)^{d}$ & $22.2(1.3-117.4)^{d}$ & $0.045^{b}$ \\
\hline \multicolumn{3}{|l|}{ Age group } & \multirow[t]{4}{*}{$0.035^{c}$} \\
\hline$<1$ year & $31(64.6 \%)$ & $17(35.4 \%)$ & \\
\hline $1 \leq$ and $<5$ years old & $123(82 \%)$ & $27(18 \%)$ & \\
\hline$\geq 5$ years old & $49(80.3 \%)$ & $12(19.7 \%)$ & \\
\hline Total fever days & $5(1-20)^{d}$ & $6(1-20)^{d}$ & $0.174^{b}$ \\
\hline Hospitalization time & $10(3-34)^{d}$ & $15(5-35)^{d}$ & $<0.001^{b}$ \\
\hline Coronary involvement & $37(17.3 \%)$ & $19(42.2 \%)$ & $<0.001^{\mathrm{a}}$ \\
\hline \multicolumn{3}{|l|}{ Type of diagnosis } & \multirow[t]{3}{*}{$0.796^{\mathrm{a}}$} \\
\hline Typical KD & $69(79.3 \%)$ & $18(20.7 \%)$ & \\
\hline Incomplete KD & $134(77.9 \%)$ & $38(22.1 \%)$ & \\
\hline \multicolumn{4}{|c|}{ a Pearson Chi-Square analysis was used. } \\
\hline \multicolumn{4}{|c|}{ c significant difference was observed in the $<1$ years age group. } \\
\hline \multicolumn{4}{|c|}{ d "Median" and "lowest - highest values" in parentheses were specified for non-normally distributed data. } \\
\hline \multicolumn{4}{|c|}{ IVIG: intravenous immunoglobulin. } \\
\hline
\end{tabular}

Laboratory findings of the patients were evaluated according to the IVIG response. The data showed statistically significant, elevated levels of white blood cells, C-reactive protein, aspartate aminotransferase, lactate dehydrogenase, troponin I, N-terminal (NT)-pro hormone BNP (NT-proBNP), triglycerid, and decreased levels of hemoglobin, hematocrit and sodium in IVIG resistant patients (Table 2). 
Table 2

Central tendency measures of laboratory findings according to IVIG treatment responsiveness

\begin{tabular}{|c|c|c|c|}
\hline \multirow[t]{2}{*}{ Variable } & IVIG responders & IVIG non-responders & \multirow[t]{2}{*}{$p$ value } \\
\hline & $(n=203)$ & $(n=56)$ & \\
\hline Sedimentation & $65.5(28.1)^{\mathrm{c}}$ & $71.6(27.9)^{\mathrm{C}}$ & $0.536^{a}$ \\
\hline WBC & $12800(1000-49570)^{d}$ & $15850(3800-33230)^{d}$ & $0.005^{b}$ \\
\hline NEU (\%) & $60.09(17.17)^{\mathrm{C}}$ & $65,44(16.31)^{\mathrm{C}}$ & $0.813^{\mathrm{a}}$ \\
\hline $\mathrm{Hb}$ & $10.64(1.49)^{\mathrm{c}}$ & $10.47(1.44)^{\mathrm{C}}$ & $0.005^{a}$ \\
\hline Hematocrit & $32.46(4.25)^{\mathrm{c}}$ & $31.63(4.02)^{\mathrm{C}}$ & $0.002^{\mathrm{a}}$ \\
\hline PLT & $381300(95000-2099000)^{d}$ & $384500(51000-1356000)^{d}$ & $0.783^{b}$ \\
\hline CRP & $65(1-431)^{d}$ & $88.8(3.1-369)^{d}$ & $0.012^{b}$ \\
\hline Albumin & $3.7(2.1-4.5)^{d}$ & $3.7(2.3-4.9)^{d}$ & $0.846^{\mathrm{b}}$ \\
\hline AST & $32(11-604)^{d}$ & $40.9(4-628)^{d}$ & $0.038^{b}$ \\
\hline ALT & $22(4-527)^{d}$ & $24(5-705)^{d}$ & $0.156^{b}$ \\
\hline LDH & $322(171-686)^{d}$ & $383(170-944)^{d}$ & $0.022^{b}$ \\
\hline Total Bilirubin & $0.22(0.03-2.79)^{d}$ & $0.26(0.09-6.54)^{d}$ & $0.363^{b}$ \\
\hline Direct Bilirubin & $0.09(0.01-2.66)^{d}$ & $0.13(0.01-6.34)^{d}$ & $0.192^{b}$ \\
\hline $\mathrm{Na}$ & $136(121-143)^{d}$ & $134(127-141)^{d}$ & $0.014^{b}$ \\
\hline Troponin I & $0.003(0.003-0.03)^{d}$ & $0.007(0.003-0.127)^{d}$ & $0.028^{b}$ \\
\hline NT-proBNP & $253(55-8149)^{d}$ & $2925(277-35000)^{d}$ & $0.004^{b}$ \\
\hline Total Cholesterol & $142(77-296)^{d}$ & $151(55-245)^{d}$ & $0.744^{\mathrm{b}}$ \\
\hline $\mathrm{HDL}$ & $21.9(10.5)^{\mathrm{C}}$ & $20.7(14.6)^{\mathrm{C}}$ & $0.704^{\mathrm{a}}$ \\
\hline LDL & $84.5(28-224)^{d}$ & $81(11-172)^{d}$ & $0.473^{b}$ \\
\hline Triglycerid & $167(57-440)^{d}$ & $219(69-550)^{d}$ & $0.016^{b}$ \\
\hline
\end{tabular}




\begin{tabular}{|c|c|c|c|}
\hline \multirow[t]{2}{*}{ Variable } & IVIG responders & IVIG non-responders & \multirow[t]{2}{*}{$p$ value } \\
\hline & $(n=203)$ & $(n=56)$ & \\
\hline \multicolumn{4}{|c|}{${ }^{a}$ Student's $t$ test was used from parametric tests. } \\
\hline \multicolumn{4}{|c|}{${ }^{b}$ Mann-Whitney $U$ test was used from non-parametric test. } \\
\hline \multicolumn{4}{|c|}{$\begin{array}{l}\text { c"Mean" and "standard deviation" values in parentheses were specified for the data that fit the normal } \\
\text { distribution. }\end{array}$} \\
\hline \multicolumn{4}{|c|}{$\begin{array}{l}\text { d"Median" and "lowest - highest values" in parentheses were specified for data that do not fit the normal } \\
\text { distribution. }\end{array}$} \\
\hline \multicolumn{4}{|c|}{$\begin{array}{l}\text { ALT: alanine transaminase; AST: aspartate aminotransferase; CRP: C-reactive protein; Hb: hemoglobin; HDL: } \\
\text { high density lipoprotein; } L D H: \text { lactate dehydrogenase; } L D L \text { : loW density lipoprotein; Na: sodium; NEU (\%): } \\
\text { neutrophil/ leukocyte percentage; PLT: platelet count; NT-proBNP: N-terminal brain natriuretic peptide } \\
\text { precursor; WBC: White blood cell count / } \mathrm{mm}^{3} \text {. }\end{array}$} \\
\hline
\end{tabular}

While coronary artery aneurysm $(Z>2.5)$ was detected in 30 (11.6\%) of the cases, coronary ectasia / dilatation was detected in 15 patients $(6 \%)(2<Z$ score $<2.5)$, and 214 ( $83 \%$ coronaries were completely normal. According to the diagnostic criteria, $33.6 \%$ were evaluated as typical KD and $66.4 \%$ as atypical (incomplete) KD.

While IVIG and aspirin, which are the standard primary treatment, are given to all patients in appropriate doses, aspirin was discontinued in 29 patients $(11 \%)$ because salicylic findings developed. Eight patients were needed intensive care due to left ventricular dysfunction secondary to myocarditis during the acute phase, while one underwent therapeutic plasmapheresis.

61 patients with IVIG response and 37 patients with IVIG resistance evaluated by all exom analysis. Based on SNP frequency, although statistically not significant, IVIG resistance risk increased with three exonic variants including "rs11556218" [OR = 2.34] in the IL 16 gene, "rs344560" [OR = 2.32] in the TNFSF14 gene and "rs12479626" [OR = 1.67] located in the NFATC2 gene; respectively (Table 3). 
Table 3

Analysis of the association of five candidate SNVs with IVIG resistance

\begin{tabular}{|c|c|c|c|c|c|c|c|c|}
\hline \multirow[t]{2}{*}{ Gene } & \multirow[t]{2}{*}{ SNV } & \multirow[t]{2}{*}{ Position } & \multirow[t]{2}{*}{ Allele } & \multirow{2}{*}{$\begin{array}{l}\text { No. of } \\
\text { samples }\end{array}$} & \multicolumn{2}{|l|}{ RAF } & \multicolumn{2}{|c|}{ Association } \\
\hline & & & & & $\begin{array}{l}\text { IVIG non- } \\
\text { responder }\end{array}$ & $\begin{array}{l}\text { IVIG } \\
\text { resp. }\end{array}$ & $\begin{array}{l}\text { OR } \\
\text { (\%95 } \\
\text { Cl) }\end{array}$ & $\mathbf{P}$ \\
\hline IL16 & rs11556218 & p.Asn1147Lys & $T / G$ & 7 & 0.108 & 0.049 & $\begin{array}{l}2.343 \\
(0.494- \\
11.116)\end{array}$ & $0.421^{a}$ \\
\hline TNFSF14 & rs344560 & p.Lys214Glu & $A / G$ & 13 & 0.189 & 0.098 & $\begin{array}{l}2.319 \\
(0.659- \\
6.945)\end{array}$ & $0.229^{a}$ \\
\hline NFATC2 & rs 12479626 & p.His446Arg & $\mathrm{C} / \mathrm{T}$ & 2 & 0.027 & 0.016 & $\begin{array}{l}1.667 \\
(0.202- \\
37.475)\end{array}$ & $1^{\mathrm{a}}$ \\
\hline DERL3 & rs1128127 & p.Ala211Val & $\mathrm{A} / \mathrm{G}$ & 28 & 0.189 & 0.344 & $\begin{array}{l}0.444 \\
(0.167- \\
1.181)\end{array}$ & $0.099^{b}$ \\
\hline SAMD9L & rs10488532 & p.Val266lle & $\mathrm{T} / \mathrm{C}$ & 20 & 0.135 & 0.246 & $\begin{array}{l}0.246 \\
(0.158- \\
1.451)\end{array}$ & $0.187^{b}$ \\
\hline $\begin{array}{l}\text { 95\% Cl: } 95 \\
\text { RAF: risk a } \\
{ }^{a} \text { Fisher's ex } \\
{ }^{b} \text { Pearson } 0\end{array}$ & $\begin{array}{l}\text { confidence in } \\
\text { ele frequency; } \\
\text { act test used } \\
\text { i-square test }\end{array}$ & $\begin{array}{l}\text { erval; A: adenine; } \\
\text { SNV: single nucle } \\
\text { as used. }\end{array}$ & $\begin{array}{l}\text { C: cytosi } \\
\text { tide vari }\end{array}$ & $\begin{array}{l}\text { e; G: guani } \\
\text { int; T: thym }\end{array}$ & $\begin{array}{l}\text { e; IVIG: intra } \\
\text { le; OR: Odds }\end{array}$ & $\begin{array}{l}\text { enous in } \\
\text { ratio; }\end{array}$ & munoglob & lin; \\
\hline
\end{tabular}

\section{Discussion}

Kawasaki disease is a self-limiting acute febrile systemic vasculitis that usually involves small and medium vessels, particularly coronary arteries. ${ }^{11}$ The most serious complication, CALs (coronary artery involvement), is reported in $15-25 \%$ of untreated cases. ${ }^{12}$ CALs coronary involvement rate was found $17.6 \%$ in our study group.

It has been reported that the probability of developing coronary artery lesions decreases with high dose IVIG treatment administered in the acute period of the disease. Therefore, the response of patients to standard therapy is an important factor that determines the risk of complications. In their study, Fabi et al. showed the frequency of CALs in the patients with IVIG response and resistance in $19.6 \%$ and $37.2 \%$, respectively $(p=$ 0.01). ${ }^{13}$ In our study, this rate was found to be $17.3 \%$ and $42.2 \%$ in the resistant group with IVIG response, respectively $(p<0.001)$.

The incidence of resistance to IVIG is generally reported in the literature between $10-20 \% .{ }^{14-16}$ Classification of patients according to the risk of IVIG resistance could inform decisions to administer more aggressive initial treatment, with the aim of reducing the risk of coronary artery lesion development. ${ }^{10}$ 
Many risk scoring systems have been developed so far with the idea of coronary complications can be reduced by using aggressive treatment regimens in the early period if the response to treatment can be predicted at the beginning of the disease. ${ }^{6-9}$ These scoring systems, which were developed based on clinical findings and laboratory parameters, have not been widely used worldwide since their prediction power varies according to the population they are applied to. ${ }^{17-21}$ In the studies conducted in Northern American Cohort, ${ }^{18}$ US Midwest, $^{19}$ Spain, ${ }^{20}$ The UK, $^{21}$ German, ${ }^{22}$ France $^{23}$ populations, IVIG resistance was found at different rates. The determination of IVIG resistance at different rates in different races led to genetic studies.

In the last ten years, with the rapid advancement of next generation sequencing techniques reserachers identified variants related to responsiveness to treatment, the risk of complications and mortality in multifactorial diseases including KD. In a recent study, Kim et al. performed WES to $296 \mathrm{KH}$ patients, in which 101 cases were IVIG resistant, and identified different SNP variants in five different gene loci related to immune response. ${ }^{10}$ They obtained a broad-based risk analysis by adding the results of replication studies of two separate cohorts with 903 with IVIG response and 352 with IVIG resistance. In GWAS analysis of these variants were: "rs11556218" (p.Asn1147Lys) [OR = 1.89 p = 0.0042] in the IL 16 gene; "rs344560" (p.Lys214Glu) [OR = $2.26 \mathrm{p}=0.0096$ ] in the TNFSF14 gene and "rs12479626" (p.His446Arg) [OR $=2.79 \mathrm{p}=0.0035$ ] located in the NFATC2 gene; "rs1128127" (p.Ala211 Val) in the DERL3 gene [OR = 2.45 p = 0.0109]; "rs10488532" (p.Val266 with) located in the $S A M D 9 L$ gene [OR $=3.46 \mathrm{p}=0.0067]$.

Here we report only three of them had an estimated relative risk (OR) greater than 1. These were localized polymorphisms in the IL 16 gene (rs11556218), the TNFSF14 gene (rs344560) and the NFATC2 gene (rs12479626), respectively. Since $p$ values $>0.05$ were not statistically significant this may be related to patient number whic is lower than Kim et al.' study.

In general, KD develops as a result of irregularity in the immune response. It has been suggested that there is a similarity between KD and the pathogenesis of autoimmune diseases. ${ }^{24} \mathrm{~T}$ lymphocytes are predominant in the immunopathogenesis of KD. Increased T lymphocyte activation leads to the production of cytokines responsible for the pathogenesis of the disease.

Interleukin-16 (IL-16) encoded by the $/ L 16$ gene is a pileiotropic cytokine that acts as a modulator in $T$ cell activation and was first described in $1982 .{ }^{25} \mathrm{IL}-16$, which shows chemoattractant function mainly on CD4 + T lymphocytes, has an effect on CD4 + / CD8 + ratio. IL-16, which showed an inhibitory role in HIV replication in the $1990 \mathrm{~s}^{26}$, has been associated with a number of diseases that progress with inflammation or autoimmunity in different studies. Disorders in the $I L 16$ gene play an important role in the pathophysiology of these diseases with CD4 + / CD8 + ratio and CD8 + T cell activation. The diseases associated with IL-16 are bronchial asthma, ${ }^{27}$ Crohn's disease ${ }^{28}$, systemic lupus erythematosus, ${ }^{29}$ rheumatoid arthritis, ${ }^{30}$ and multiple myeloma. ${ }^{31}$ IL 16 variant of "rs11556218 (T / G)" identified by Kim et al. ${ }^{10}$ On IVIG resistance in IL16 gene in KD was associated with a predisposition to multiple sclerosis. ${ }^{32}$

TNFSF14 gene encodes one of the tumor necrosis factor (TNF) ligands. The receptor to which it binds is a member of the tumor necrosis factor receptor superfamily (TNFRSF14) and is also known as the herpesvirus entry mediator (HVEM). The encoded protein provides co-stimulation for T cell activation. In this way, it plays a 
preventive role in herpesvirus infections. It has also been shown to stimulate $\mathrm{T}$ cell proliferation and trigger apoptosis of various tumor cells. ${ }^{33}$

NFATC2 gene is a member of the nuclear factor (NFAT: Nuclear factor of activated T-cells) family of activated T cells, and the product it encodes is a DNA-binding protein. The protein contained in the T cell cytosol induces nuclear transcription complexes by binding to the nucleus when the T cell receptor (TCR) is activated. ${ }^{34}$ Nuclear Factor of Activated T cells (NFAT) family members are known for their roles in T cell development and activation but still largely undetermined in CD8 + T cell differentiation in vivo. NFAT1 and NFAT2 in T cells display a significant increase in KLRG1hi CD127hi population and are unable to clear an acute viral infection. ${ }^{35}$ NFAT-deficient CTLs showed different degrees of impaired IFN-ץ and TNF-a expression with NFAT1 being mainly responsible for IFN-y production upon ex-vivo stimulation as well as for antigen-specific cytotoxicity.

SAMD9L is adjacent to its close paralog sterile alpha motif domain-containing protein 9 (SAMD9) on chromosome 7q21.2 and encodes a cytoplasmic protein that has important roles in multiple cellular processes such as cell proliferation (most likely as a tumor suppressor), the neoplastic phenotype, and the innate immune response to viral infection. ${ }^{36,37}$ The physiological functions of SAMD9L currently remain poorly understood, but its importance has recently been emphasized during the discovery of the genetic cause of a rare, lifethreatening human disease. ${ }^{38}$ In the study Kim at al., although associations between SAMD9L variants and KD susceptibility or IVIG resistance have not been reported, it is most likely that the role of SAMD9L in IVIG resistance could be mediated through various immune signaling pathways in which SAMD9L plays important roles in immune-related diseases. ${ }^{39}$

\section{Conclusion}

Our study is associated with three genes related to T cell activation (IL16, TNFSF14, NFATC). From this point of view, it can be said that T cell activation has an important role in IVIG resistance pathogenesis. Determination of factors that increase the risk of developing coronary artery aneurysm and IVIG resistance with all exom gene analysis will be helpful in determining the diagnosis, treatment and complications of the disease.

\section{Abbreviations}

AHA - American Heart Association

CAA - coronary artery aneurysm

IVIG - intravenous immunoglobulin

GWAS - genome-wide association studies

KD - Kawasaki disease

SNPs - single nucleotide polymorphisms

\section{Declarations}




\section{Ethical Approval and Consent to participate}

The study protocol was approved by the University of Health Science, Kanuni Sultan Süleyman Research and Training Hospital Human Investigation Committee (HIC) (protocol number 48865165-302.14.01). Informed consent forms were signed by the parents.

\section{Consent for publication}

Not applicable.

\section{Availability of supporting data}

The dataset used and/or analyzed during the current study are available from the corresponding author on reasonable request.

\section{Competing interests}

The authors have no conflicts of interest to disclose.

\section{Funding}

No specific funding was received from any bodies in the public, commercial or not-for-profit sectors to carry out the work described in this article.

\section{Authors' contributions}

YZV reviewed the literature, contacted the parents of the patients and examined them, took blood samples, collected data about the disease, performed statistical analysis of the data of the cases and contributed to the writing of the article. $\mathrm{KO}$ and $\mathrm{AOC}$ conceptualized and designed the work, provided general direction and planning, encouraged $Y Z V$, reviewed and revised the article, supervised the project. MG and KB provided the physical and material requirements required to perform the whole exome analysis from the blood samples taken in the study. All authors approved the final manuscript as submitted and agree to be accountable for all aspects of the work.

\section{Acknowledgements}

We thank the families for participating in this study. Authors are grateful to Shrikant Mane for his support in whole exom sequencing studies of the project.

\section{Authors' information}

\section{Affiliations}

Department of Pediatrics, Basaksehir Cam and Sakura City Hospital, University of Health Science, Istanbul, 34303, Turkey

Yusuf Ziya Varli 
Department of Medical Genetics, School of Medicine, Dokuz Eylul University, Izmir, 35340, Turkey

Ahmet Okay Caglayan

Department of Genetics, Yale Center for Genome Analysis, Yale School of Medicine, New Haven, 06510, CT, USA

Kaya Bilguvar

Departments of Neurosurgery, Neurobiology and Genetics. New Haven, CT 06520-8082, USA

Murat Gunel

Department of Pediatric Cardiology, Demiroglu Bilim University, Istanbul, 34303, Turkey

Kazim Oztarhan

\section{References}

1. Kawasaki T. Acute febrile mucocutaneous syndrome with lymphoid involvement with specific desquamation of the fingers and toes in children [in Japanese]. Arerugi. 1967;16:178-222. PMID: 6062087.

2. McCrindle BW, Rowley AH, Newburger JW, et al. Diagnosis, Treatment, and Long-Term Management of Kawasaki Disease: A Scientific Statement for Health Professionals From the American Heart Association. Circulation. 2017;135(17):e927-999. doi: 10.1161/CIR.0000000000000484.

3. Newburger JW, Takahashi M, Gerber MA, et al. Diagnosis, treatment, and longterm management of Kawasaki disease:. A statement for health professionals from the committee on rheumatic fever, endocarditis, and Kawasaki disease, council on cardiovascular disease in the young, American Heart Association. Circulation. 2004 Oct 26;110(17):2747-2771. doi: 10.1161/01.CIR.0000145143.19711.78.

4. Moffett BS, Syblik D, Denfield S, Altman C, Tejtel-Sexson K. Epidemiology of immunoglobulin resistant Kawasaki disease: results from a large, national database. Pediatr Cardiol. 2015;36(2):374-378. doi: 10.1007/s00246-014-1016-1.

5. Burns JC, Franco A. The immunomodulatory effects of intravenous immunoglobulin therapy in Kawasaki disease. Expert Rev Clin Immunol. 2015;11:819-825. doi: 10.1586/1744666X. 2015.1044980. doi: 10.1586/1744666x.2015.1044980.

6. Kobayashi T, Inoue Y, Morikawa A. Risk stratification and prediction of resistance to intravenous immunoglobulin in Kawasaki disease [in Japanese]. Nihon Rinsho. 2008;66(2):332-337. PMID: 18260333.

7. Harada K. Intravenous gamma-globulin treatment in Kawasaki disease. Acta Paediatr Jpn. 1991;33(6):805-810. doi: 10.1111/j.1442-200x.1991.tb02612.x.

8. Sano T, Kurotobi S, Matsuzaki K, et al. Prediction of non-responsiveness to standard high-dose gammaglobulin therapy in patients with acute Kawasaki disease before starting initial treatment. Eur $J$ Pediatr. 2007;166:131-137. doi: 10.1007/s00431-006-0223-z. 
9. Egami K, Muta $\mathrm{H}$, Ishii M, et al. Prediction of resistance to intravenous immunoglobulin treatment in patients with Kawasaki disease. J Pediatr. 2006;149(2):237-240. doi: 10.1016/j.jpeds.2006.03.050.

10. Kim HJ, Kim JJ, Yun SW, et al. Association of the IL16 Asn1147Lys polymorphism with intravenous immunoglobulin resistance in Kawasaki disease. J Hum Genet. 2020;1-6. doi: 10.1038/s10038-020-07212.

11. Li X, Chen $Y$, Tang $Y$, et al. Predictors of intravenous immunoglobulin-resistant Kawasaki disease in children: a meta-analysis of 4442 cases. Eur J Pediatr. 2018;177(8):1279-1292. doi: 10.1007/s00431-0183182-2.

12. Woo HO. Predictive risk factors of coronary artery aneurysms in Kawasaki disease. Korean J Pediatr. 2019;62(4):124. doi: 10.3345/kjp.2019.00073.

13. Fabi M, Andreozzi L, Corinaldesi E, et al. Inability of Asian risk scoring systems to predict intravenous immunoglobulin resistance and coronary lesions in Kawasaki disease in an Italian cohort. Eur J Pediatr. 2019;178(3):315-322. doi: 10.1007/s00431-018-3297-5.

14. Nakamura $Y$, Yashiro M, Uehara R, et al. Epidemiologic features of Kawasaki disease in Japan: results of the 2009-2010 nationwide survey. J Epidemiol. 2012;22(3):216-221. doi: 10.2188/jea.je20110126.

15. Nakamura Y, Yashiro M, Uehara R, Oki I, Watanabe M, Yanagawa H. Epidemiologic features of Kawasaki disease in Japan: results from the nationwide survey in 2005-2006. J Epidemiol. 2008;18:167-172. doi: 10.2188/jea.je2008001.

16. Son MB, Gauvreau K, Ma L, et al. Treatment of Kawasaki disease: analysis of 27 US pediatric hospitals from 2001 to 2006. Pediatrics. 2009;124:1-8. doi: 10.1542/peds.2008-0730.

17. Tremoulet AH, Best BM, Song S, et al. Resistance to intravenous immunoglobulin in children with Kawasaki disease. J Pediatr. 2018;153:117-121. doi: 10.1016/j.jpeds.2007.12.021.

18. Sleeper LA, Minich LL, McCrindle BM, et al. Evaluation of Kawasaki disease risk-scoring systems for intravenous immunoglobulin resistance. J Pediatr. 2011;158(5):831-835e3. doi:

10.1016/j.jpeds.2010.10.031.

19. Loomba RS, Raskin A, Gudausky TM, Kirkpatrick E. Role of the Egami score in predicting intravenous immunoglobulin resistance in Kawasaki disease among different ethnicities. Am J Ther. 2016;23(6):e1293-1299. doi: 10.1097/mjt.0000000000000045.

20. Sánchez-Manubens J, Antón J, Bou R, et al. Role of the Egami score to predict immunoglobulin resistance in Kawasaki disease among a Western Mediterranean population. Rheumatol Int. 2016;36(7):905-910. doi: 10.1007/s00296-016-3499-y.

21. Davies S, Sutton N, Blackstock S, et al. Predicting IVIG resistance in UK Kawasaki disease. Arch Dis Child. 2015;100:366-368. doi: 10.1136/archdischild-2014-307397.

22. Jakob A, Horstmann J, Hufnagel M, et al. Failure to predict high-risk Kawasaki disease patients in a population-based study cohort in Germany. Pediatr Infect Dis. 2018;37(9):850-855. doi: 10.1097/inf.0000000000001923.

23. Piram M, Bello MD, Tellier S, et al. Defining the risk of first intravenous immunoglobulin unresponsiveness in non-Asian patients with Kawasaki disease. Sci Rep. 2020;10(1):3125. doi: 10.1038/s41598-020-599727. 
24. Guo MM-H, Tseng W-N, Ko C-H, Pan H-M, Hsieh K-S, Kuo H-C. Th17- and Treg-related cytokine and mRNA expression are associated with acute and resolving Kawasaki disease. Allergy [Internet]. 2015;70(3):310318. doi: 10.1111/all.12558.

25. Cruikshank WW, Kornfeld H, Center DM. Interleukin-16. J. Leukoc. Biol. 2000;67(6):757-766. doi: 10.1002/jlb.67.6.757.

26. Baier M, Werner A, Bannert N, Metzner K, Kurth R. HIV suppression by interleukin-16. Nature. 1995;378(6557):563. doi: 10.1038/378563a0.

27. Laberge S, Ernst P, Ghaffar O, et al. Increased expression of interleukin-16 in bronchial mucosa of subjects with atopic asthma. Am J Respir Cell Mol Biol. 1997;17(2):193-202. doi: 10.1165/ajrcmb.17.2.2750.

28. Middel P, Reich K, Polzien F, et al. Interleukin 16 expression and phenotype of interleukin 16 producing cells in Crohn's disease. Gut. 2001;49(6):795-803. doi: 10.1136/gut.49.6.795.

29. Matsushita M, Hayashi T, Ando S, et al. Changes of CD4/CD8 ratio and interleukin-16 in systemic lupus erythematosus. Clin Rheumatol. 2000;19(4):270-274. doi: 10.1007/pl00011171.

30. Blaschke S, Schulz H, Schwarz G, Blaschke V, Müller GA, Reuss-Borst M. Interleukin 16 expression in relation to disease activity in rheumatoid arthritis. J Rheumatol. 2001;28(1):12-21. PMID: 11196512.

31. Koike M, Sekigawa I, Okada M, et al. Relationship between CD4(+)/CD8(+) T cell ratio and T cell activation in multiple myeloma: reference to IL-16. Leuk Res. 2002;26(8):705-711. doi: 10.1016/s01452126(01)00192-8.

32. Farrokhi M, Masoudifar A, Derakhshan A, et al. The association of interleukin-16 gene polymorphisms with il-16 serum levels and risk of multiple sclerosis. Immunol Invest. 2017;1-9. doi: 10.1080/08820139.2016.1268154.

33. Tamada K, Shimozaki K, Chapoval Al, et al. LIGHT, a TNF-like molecule, costimulates T cell proliferation and is required for dendritic cell-mediated allogeneic T cell response. J Immunol. 2000;164(8):4105-4110. doi: 10.4049/jimmunol.164.8.4105.

34. Rengarajan J, Tang B, Glimcher LH. NFATc2 and NFATc3 regulate T(H)2 differentiation and modulate TCRresponsiveness of naive T(H)cells. Nat Immunol. 2002;3:48-54. doi: 10.1038/ni744.

35. Xu T, Keller A, Martinez GJ. NFAT1 and NFAT2 differentially regulate CTL differentiation upon acute viral infection. Front Immunol. 2019;10:184. doi: 10.3389/fimmu.2019.00184.

36. Li CF, MacDonald JR, Wei RY, et al. Human sterile alpha motif domain 9, a novel gene identified as downregulated in aggressive fibromatosis, is absent in the mouse. BMC Genomics. 2007;8:92. doi: 10.1186/1471-2164-8-92.

37. Wang Q, Zhai YY, Dai JH, Li KY, Deng Q, Han ZG. SAMD9L inactivation promotes cell proliferation via facilitating G1-S transition in hepatitis B virus-associated hepatocellular carcinoma. Int J Biol Sci. 2014;10:807-816. doi: 10.7150/ijbs.9143.

38. Lemos de Matos A, Liu J, McFadden G, Esteves PJ. Evolution and divergence of the mammalian SAMD9/SAMD9L gene family. BMC Evol Biol. 2013;13:121. doi: 10.1186/1471-2148-13-121.

39. Kim JJ, Yun SW, Yu JJ, et al. Identification of SAMD9L as a susceptibility locus for intravenous immunoglobulin resistance in Kawasaki disease by genome-wide association analysis.

Pharmacogenomics J. 2020;20(1):80-86. doi: 10.1038/s41397-019-0085-1. 